\title{
EFFECT OF PRECIPITATION PATTERN ON LEACHING OF PRESERVATIVE FROM TREATED WOOD AND IMPLICATIONS FOR ACCELERATED TESTING
}

Stan Lebow

\begin{abstract}
There is a need to develop improved accelerated test methods for evaluating the leaching of wood preservatives from treated wood exposed to precipitation. In this study the effects of rate of rainfall and length of intervals between rainfall events on leaching was evaluated by exposing specimens to varying patterns of simulated rainfall under controlled laboratory conditions. Lumber specimens were pressure-treated with 0,5 ; 1 or $2, \%$ solutions of chromated copper arsenate (CCA) and exposed to $762 \mathrm{~mm}$ of rainfall at rates of 2,5; 8 or $25 \mathrm{~mm} / \mathrm{h}$. Intervals between rainfall events were increased for some specimens. Leachate was periodically collected and analyzed to quantify leaching of arsenic, chromium and copper. The quantity of CCA elements leached, per unit rainfall, was consistently greatest at the lowest rainfall rate for all solution concentrations evaluated. Incorporation of additional time between rain events increased leaching at the lowest rainfall rate, but this effect was less noticeable as rainfall rate increased. The results of this study indicate that simulated rainfall leaching tests should be conducted using rainfall intensities at the lower end of those that are typical for the region of interest. The lengths of intervals between rainfall events may also increase leaching, but use of lengthy resting intervals conflicts with the goal of accelerated testing. Further research may be warranted to optimize time between rainfall events and assess the effect of drying periods between rainfall events.
\end{abstract}

Keywords: Wood preservative, leaching, accelerated testing, precipitation, rainfall intensity.

\section{INTRODUCTION}

Leaching of biocide from treated wood is of importance in both the long-term durability of the treated product and its potential for impacting the natural environment. The role of resistance to leaching in durability is clear as the wood product may fail prematurely if the concentration of biocide remaining in the wood falls below that needed to prevent biodeterioration. The significance of potential environmental impacts associated with leaching of biocides is less clear, but concerns have been expressed by governmental regulatory and advisory bodies, and use of biocide-treated wood has been limited in some situations. There is increasing world-wide interest in the development of test methods to estimate the quantity of these emissions so that potential environmental impacts can be assessed (Lebow et al. 2008, Ruddick 2008). However, obtaining useful and representative estimates of biocide leaching from treated wood can be challenging. In the past, much interest in preservative leaching and environmental impact was focused on treated wood that was immersed in water, such as marine piles. In most structures however, the greatest proportion of treated wood is not in direct contact with soil or standing water, and more recently the need to characterize emissions from treated wood used above-ground or above water has been recognized (Hasan et al. 2010, Tao et al. 2013). 
The current standardized leaching methods were primarily developed to allow comparison between experimental formulations and provide information on leach resistance as it related to long term durability (Hingston et al. 2001). These methods, which are primarily intended for water-based preservatives, utilize continuous immersion of small specimens with the goal of accelerating and amplifying leaching. In the United States, for example, the American Wood Protection Association (AWPA) Method E11-12, Standard Method for Accelerated Evaluation of Preservative Leaching, specifies vacuum impregnation of small (19 $\mathrm{mm})$ cubes with water, followed by continuous immersion for 14 days (AWPA 2013a). Japanese (JIS K 1571), Chinese (CNS 6717) and European (EN 84) methods utilize leaching as a weathering step in preparing specimens for exposure to biological attack (EN 84 1997, CNS 2000, JSA 2004). These methods also specify immersion of small specimens for prolonged periods and are expected to greatly accelerate leaching.

More recently, the Organization for Economic Cooperation and Development (OECD) has developed guidelines for evaluating biocide release from preservative-treated wood, and these methods are intended for use in estimating release from in-service products (Baines 2005, Cooper 2011, OECD 2007, OECD 2009, Schoknecht 2005, Schoknecht et al. 2004, Temiz, et al. 2006). Separate methods are recommended for wood that is intended for use immersed in water versus wood that is to be used above-ground or above water. For wood to be immersed in water, the method is similar to EN-84 (1997) (OECD 2007). For wood used aboveground, OECD guidelines describe an approach involving brief dip immersions utilizing small (15 by 25 by $50 \mathrm{~mm}$ ) specimens (OECD 2009). Although intended to simulate in-service leaching, there is some concern that this approach may not represent commercially produced lumber (Baines 2005) or produce the moisture conditions reported for wood products exposed to natural weathering (Lebow et al. 2008). One study which compared outdoor leaching to the OECD method concluded that the laboratory method risked underestimating in-service leaching (Morsing and Lindegaard 2004).

Because the extent and pattern of preservative release is dependent on both test method and type of preservative, it is difficult to anticipate how well a particular test method will estimate long-term release from a new type of preservative (Lebow et al. 2008). This problem suggests that it may be worthwhile to develop test methods that more closely simulate naturally occurring precipitation. Several researchers have used some form of simulated rainfall to evaluate preservative leaching (Cooper and MacVicar 1995, Lebow et al. 2003, Lebow et al. 2004, Mitsuhashi et al. 2007, Morrell et al. 2004). Simulated rainfall methods have the potential for relatively close simulation of natural rainfall events and have the additional advantage of allowing extrapolation based on volume of rainfall.

Development of a simulated rainfall method for evaluating above-ground leaching requires some understanding of how precipitation affects wood moisture and thus the potential for leaching. Researchers have reported that the moisture content of pine sapwood exposed to natural weathering may range from maximums of $80 \%$ to minimums of approximately 10\% (Belford and Nicholson 1969, Edlund and Sundman 1989, Hedley et al. 2004, Lindegaard and Morsing 2003, Militz et al. 1998, Rapp et al. 2000, Rydell et al. 2005, Saldis and Rapp 2004). Most of the maximums reported fell within $40 \%$ to $55 \%$ for horizontal specimens and between $30 \%$ and $50 \%$ for vertical specimens. Minimum moisture contents generally fell into the $10 \%$ to $15 \%$ range. Average moisture contents reported for horizontal exposures ranged from $21 \%$ to $26 \%$, whereas the averages reported for vertical exposure were $18,6 \%$ and 25,4\%. Moisture contents reported for less permeable species such as Picea spp. (Spruce) or Pseudostsuga menziesii (Douglas-fir) tended to be lower than those of pine species when exposed under similar conditions (Brischke and Rapp 2008, Hedley et al. 2004, Lindegaard and Morsing 2003).

Previous studies of treated wood exposed to natural weathering have also indicated that both the pattern and rate of rainfall influence the quantity of preservative released. When expressed on the basis of mass of preservative leached per unit rainfall, greater amounts of biocide appear to be released at slower rainfall rates (Cockroft and Laidlaw 1978, Cooper 2003, Evans 1987), presumably because the wood is wetted for a longer period and a greater proportion of the rainfall is absorbed by the wood. However, one laboratory study found 
that rate of rainfall had little effect on leaching of pentachlorophenol from pressure-treated wood (Simonsen et al. 2008). In addition, the interval between rainfall events has been reported to influence leaching, with greater amounts leached after longer resting periods. This type of effect has been attributed to the allowance for a longer period for soluble preservative components to diffuse to the surface from the interior of the wood products (Chung and Ruddick 2004, Hasan et al. 2010, Ruddick 2008, Tao et al. 2013, Taylor and Cooper 2005). At least one study, however, found little relationship between the length of the interval between rainfall events and the subsequent concentrations of preservative metals in leachate (Morrell et al. 2010). In general, the effects of rainfall rate and length of interval between rainfall periods have been difficult to evaluate because of the precipitation patterns in natural weathering are uncontrolled and confounded by variations in other factors such as temperature and humidity. In this paper we attempt to provide further insight into the role of rate of rainfall and intervals between rainfall events, on above-ground leaching by exposing matched treated specimens to varying patterns of simulated rainfall under controlled laboratory conditions.

\section{MATERIALS AND METHODS}

Lumber specimens pressure-treated at the USDA, Forest Products Laboratory, with one of three chromated copper arsenate (CCA) concentrations were exposed to one of three rates of simulated rainfall (Table 1). Additional specimens were included at one of the preservative concentrations to determine how the length of time between rainfall events affected leaching.

Table 1. Summary of treatment groups and conditions evaluated.

\begin{tabular}{clcccc}
\hline $\begin{array}{c}\text { CCA } \\
\begin{array}{c}\text { Solution } \\
\text { Concentration }\end{array}\end{array}$ & Wood Species & $\begin{array}{c}\text { Rainfall } \\
\text { Rates } \\
(\mathrm{mm} / \mathrm{h})\end{array}$ & $\begin{array}{c}\text { Replicate } \\
\text { Trials }\end{array}$ & $\begin{array}{c}\text { Replicate } \\
\text { Specimens } \\
\text { per trial }\end{array}$ & $\begin{array}{c}\text { Additional rest periods } \\
\text { between rain events }\end{array}$ \\
\hline $0,5 \%$ & Pinus spp. ${ }^{2}$ & $2,5,8,25$ & 3 & 3 & No additional (base) \\
$1,0 \%$ & Pinus spp. & $2,5,8,25$ & 3 & 3 & No additional (base) \\
$1,0 \%$ & Pinus spp. & $2,5,8,25$ & 1 & 3 & Doubled rest periods \\
$1,0 \%$ & Pinus spp. & $2,5,8,25$ & 1 & 3 & Tripled rest periods \\
$2,0 \%$ & Pinus spp. & $2,5,8,25$ & 3 & 3 & No additional (base) \\
$2,0 \%$ & T. heterophylla & $2,5,8,25$ & 3 & 3 & No additional (base) \\
\hline \hline
\end{tabular}

a. From the Southern pine species group of the southeastern U.S. Primarily Pinus taeda (loblolly pine).

b. Tsuga heterophylla (western hemlock)

\section{Specimen Preparation}

Lumber of the Southern pine species group (primarily Pinus taeda, Loblolly pine) was cut to obtain 38 by 140 by $254 \mathrm{~mm}$ long specimens that were comprised entirely of sapwood. Prior to treatment with preservative, the specimens were conditioned to ambient indoor conditions ( $6-10 \%$ moisture content) and end-sealed with neoprene rubber coating. An additional set of Western hemlock specimens was similarly prepared and evaluated at one preservative concentration. Tsuga heterophylla (Western hemlock) was included as a representative of a less permeable wood species that is often treated with wood preservatives. 


\section{Preservatives and Treatment}

The preservative selected for this study was CCA Type C (CCA-C), a preservative that has been widely used for several decades. Although use of CCA-C has been restricted in some countries, it remains one of the most well-known preservatives and has been the subject of the greatest volume of wood preservative leaching research. CCA-C also has the advantage of providing three relatively readily analyzed elements with varying leaching rates and fixation mechanisms (Lebow 1996). CCA-C contains $47,5 \%$ chromium $\left(\mathrm{CrO}_{3}\right.$ basis), 34,0\% arsenic ( $\mathrm{As}_{2} \mathrm{O}_{5}$ basis), and 18,5\% copper (CuO basis) (AWPA Standard P23, AWPA 2013b). This formulation was evaluated with treatment solutions containing $0,5,1,0 \%$ and $2 \%$ actives.

All specimens were pressure-treated in a single charge using a $81 \mathrm{kPa}$ (gauge) initial vacuum for 30 minutes followed by pressure of $1034 \mathrm{kPa}$ (gauge) for 60 minutes. Each specimen was individually weighed before and after treatment to determine uptake of preservative solution. Following treatment specimens were placed in plastic bags for one week at $23 \mathrm{C}$ to allow completion of the "fixation" reactions that minimize leaching of CCA components (Lebow 1996). The specimens were then allowed to air dry and equilibrate at $23{ }^{\circ} \mathrm{C}$ and $65 \%$ relative humidity.

\section{Assay of Samples for Preservative Retention}

Each specimen was assayed for arsenic, copper and chromium content in a manner similar to that used to determine retention in commercial charges. A drill was used to remove samples of wood 9,5 $\mathrm{mm}$ in diameter and $15 \mathrm{~mm}$ in depth from the narrow faces of each specimen. The resulting shavings were digested and analyzed in accordance with AWPA Standard A21-08, Analysis of Wood and Treating Solutions by Inductively Coupled Plasma Emission Spectrometry (AWPA 2013c). The resulting holes in the specimens were sealed with silicone caulk. Based on this assay, the treated specimens contained between 0,8 and 3,2 grams of arsenic and chromium, and between 0,4 and 1,8 grams of copper, depending on the solution concentration and wood species (Table 2).

\section{Leaching Methodology}

A simulated rainfall apparatus was constructed and used to spray room temperature $\left(21-25^{\circ} \mathrm{C}\right)$ deionized water onto the wide faces of the specimens. Ten air-atomizing, wide-angle, round spray nozzles were supported on a 1,2- by 2,4 $\mathrm{m}$ wire grid at a height of $1 \mathrm{~m}$ above the specimens. Each nozzle was supplied with air and water through a flexible hose. The rate of rainfall was controlled by adjusting the ratio of air: water pressure supplied to the nozzles. Lumber specimens were randomly assigned to a rainfall rate and to a location within the rainfall chamber. The specimens were placed horizontally in individual trays with a wide face of the specimen facing up. The trays were equipped with drains so that water draining from each specimen could be collected. Specimens were supported so that they did not contact standing water in the tray. 
Table 2. Average initial retention and total mass leached for each treatment group and leaching conditions.

\begin{tabular}{|c|c|c|c|c|c|c|c|c|}
\hline \multirow{2}{*}{$\begin{array}{l}\text { Percent } \\
\text { solution/ } \\
\text { species }\end{array}$} & \multirow{2}{*}{$\begin{array}{l}\text { Rainfall } \\
\text { rate } \\
(\mathrm{mm} / \mathrm{h})\end{array}$} & \multirow{2}{*}{$\begin{array}{c}\text { Total } \\
\text { Hours of } \\
\text { Rain/Rest }\end{array}$} & \multicolumn{3}{|c|}{ Average Initial Retention (g) } & \multicolumn{3}{|c|}{ Average Total Mass Leached (mg) } \\
\hline & & & Arsenic & Chromium & Copper & Arsenic & Chromium & Copper \\
\hline $0,5 \%$ & 2,5 & $302 / 130$ & $0,81(0,13)$ & $0,86(0,16)$ & $0,48(0,10)$ & $107,0(68,8)$ & $12,1(8,2)$ & $10,5(8,3)$ \\
\hline Pinus & 8 & $95 / 337$ & $0,80(0,10)$ & $0,84(0,10)$ & $0,47(0,07)$ & $75,9(67,9)$ & $6,5(3,2)$ & $6,5(3,6)$ \\
\hline spp. ${ }^{\mathrm{c}, \mathrm{d}}$ & 25 & $30 / 402$ & $0,84(0,13)$ & $0,87(0,13)$ & $0,47(0,07)$ & $40,7(29,9)$ & $4,9(3,4)$ & $4,3(3,7)$ \\
\hline $1,0 \%$ & 2,5 & $302 / 130$ & $1,61(0,27)$ & $1,66(0,29)$ & $0,90(0,15)$ & $28,8(5,1)$ & $6,8(3,9)$ & $9,2(4,2)$ \\
\hline Pinus & 8 & $95 / 337$ & $1,68(0,26)$ & $1,72(0,27)$ & $0,94(0,17)$ & $16,8(5,9)$ & $4,0(2,3)$ & $5,9(3,2)$ \\
\hline spp. ${ }^{\mathrm{d}}$ & 25 & $30 / 402$ & $1,75(0,21)$ & $1,76(0,21)$ & $0,98(0,09)$ & $10,7(6,8)$ & $4,0(3,2)$ & $5,4(4,8)$ \\
\hline $1,0 \%$ & 2,5 & $302 / 260$ & $1,70(0,07)$ & $1,61(0,05)$ & $0,94(0,07)$ & $45,7(8,1)$ & $14(5,5)$ & $15,5(4,4)$ \\
\hline Pinus & 8 & $95 / 674$ & $1,75(0,23)$ & $1,90(0,19)$ & $1,04(0,17)$ & $21,2(6,3)$ & $6,2(2,5)$ & $9,3(4,7)$ \\
\hline spp. $^{\text {e }}$ & 25 & $30 / 804$ & $1,87(0,04)$ & $1,89(0,02)$ & $0,96(0,05)$ & $7,6(2,0)$ & $3,3(0,8)$ & $4,5(1,6)$ \\
\hline $1,0 \%$ & 2,5 & $302 / 390$ & $1,69(0,16)$ & $1,64(0,14)$ & $0,91(0,11)$ & $51,1(11,5)$ & $12,4(6,1)$ & $12,5(5,6)$ \\
\hline Pinus & 8 & $95 / 1011$ & $1,64(0,03)$ & $1,75(0,07)$ & $1,03(0,05)$ & $21,6(9,4)$ & $4,2(0,4)$ & $6,5(2,1)$ \\
\hline Spp. ${ }^{\mathrm{e}}$ & 25 & $30 / 1206$ & $1,65(0,14)$ & $1,68(0,22)$ & $0,90(0,05)$ & $11,0(4,7)$ & $3,5(1,3)$ & $4,8(2,8)$ \\
\hline $2,0 \%$ & 2,5 & $302 / 130$ & $3,01(0,32)$ & $3,08(0,31)$ & $1,71(0,16)$ & $21,3(13,2)$ & $5,6(2,3)$ & $13,9(9,8)$ \\
\hline Pinus & 8 & $95 / 337$ & $2,90(0,72)$ & $3,16(0,35)$ & $1,78(0,25)$ & $9,2(5,8)$ & $3,1(1,9)$ & $6,5(3,9)$ \\
\hline Spp. ${ }^{\mathrm{d}}$ & 25 & $30 / 402$ & $3,11(0,29)$ & $3,12(0,30)$ & $1,66(0,17)$ & $4,5(2,9)$ & $2,6(1,7)$ & $4,2(2,5)$ \\
\hline $2,0 \%$ & 2,5 & $302 / 130$ & $2,15(1,44)$ & $2,27(1,48)$ & $1,13(0,85)$ & $13,4(4,7)$ & $0,5(0,3)$ & $0,9(0,7)$ \\
\hline T. heter- & 8 & $95 / 337$ & $1,95(0,69)$ & $2,09(0,74)$ & $1,03(0,41)$ & $5,6(4,1)$ & $0,4(0,3)$ & $0,5(0,2)$ \\
\hline ophylla ${ }^{d_{1} f}$ & 25 & $30 / 402$ & $2,48(1,20)$ & $2,57(1,21)$ & $1,30(0,66)$ & $4,5(3,5)$ & $0,4(0,3)$ & $0,8(0,6)$ \\
\hline
\end{tabular}

a. Values in parentheses represent one standard deviation from the mean.

b. Combined hours of rainfall/combined hours of intervals between rainfall events.

c. From the Southern pine species group of the southeastern U.S. Primarily Pinus taeda (Loblolly pine).

d. Average and standard deviation of nine replicates (three trials with three replicates per trial).

e. Average and standard deviation of three replicates.

f. Tsuga heterophylla (Western hemlock).

Three rainfall rates $(2,5 ; 8$ or $25 \mathrm{~mm} / \mathrm{h})$ were evaluated, and hours of spray were adjusted so that specimens were exposed to $760 \mathrm{~mm}$ of rainfall, which is slightly above the U.S. national average annual rainfall of $740 \mathrm{~mm}$ (NOAA 2013). To simulate the wetting and drying of rainfall episodes, intervals were incorporated between rainfall events for all specimens. The length of these intervals necessarily increased with increasing rainfall rate (Table 2). For the "base" specimens (those without increased time between rain events) the length of the trial was 19 days and specimens were exposed to approximately 20;6,4 or 2 hours (depending on rainfall rate) of rainfall per day, 5 days per week, for 3 consecutive weeks. No rainfall was applied over the two weekends encompassed within each trial, thus providing two periods of at least 48 consecutive hours without rainfall.

For the "base" specimens without additional time between rain events, three replicate trials were conducted for each of the three rainfall rates, and three replicate specimens per treatment group were included in each trial. The specimens used to evaluate the effect of longer intervals between rain events on leaching were exposed over either 6 weeks (specimens with doubled resting periods) or 9 weeks (specimens with tripled resting periods). Covers were placed over the specimens assigned to longer resting periods to prevent rainfall during some rain events. Covers were used (rather than simply removing the specimens) to minimize drying during the additional resting periods. For example, specimens assigned to the tripled resting periods and exposed to rainfall at a rate of $2,5 \mathrm{~mm} / \mathrm{h}$ had 302 hours of rain and 390 hours of rest, while the comparable "base" specimens also had 302 hours of rain but only 130 hours of rest (Table 2). To incorporate the longer resting periods, specimens were exposed across either two (doubled resting periods) or three (tripled resting periods) replicate trials of the "base" specimens. The effect of longer resting periods was also evaluated with three replicate specimens, but in contrast to specimens with the "base" resting periods, trials of specimens with the doubled or tripled resting periods were not replicated (Table 1). 
The rainwater draining from each specimen was collected and analyzed at 8 intervals during each trial. Regardless of the rainfall rate or schedule, collections were made after specimens had received 20,76, 127, $254,381,508,634$ and $760 \mathrm{~mm}$ of rainfall. Shorter intervals were used at the start of each trial in anticipation of an initial period of relatively rapid leaching. At each collection the water was weighed, acidified with nitric acid, and sub-sampled for analysis. The collection container was then emptied before reattachment to the specimen tray. The leachate samples were analyzed for arsenic, chromium and copper by inductively coupled plasma atomic emission spectrometry (ICP-AES) (Jobin Yvon Ultima, Horiba Scientific). The detection limits of the method were approximately $5 \mathrm{ug} / \mathrm{l}$ for arsenic and $2 \mathrm{ug} / \mathrm{l}$ for chromium and copper.

\section{RESULTS AND DISCUSSION}

\section{Effect of Rate of Rainfall on Leaching}

Leaching of arsenic, chromium and copper appeared to be greatest at the slowest rainfall rate for all CCA-C solution concentrations (Table 2, Figure 1). Total release of each element was generally $2-5$ times greater at a rainfall rate of $2,5 \mathrm{~mm} / \mathrm{h}$ than at $25 \mathrm{~mm} / \mathrm{h}$. An analysis of variance of the three replicate trials confirmed that the effect of rainfall rate on percent CCA element leached was significant for arsenic (p-value $=0,021)$ and marginally significant for chromium ( $\mathrm{p}$-value $=0,068)$ and copper $(\mathrm{p}$-value $=0,0578)$. A similar effect was also observed for arsenic release from Tsuga heterophylla (Western hemlock), but chromium and copper release from Western hemlock was not consistently affected by rainfall rate. Chromium and copper concentrations in many of the leachate samples from western hemlock were below detection limits, and this may have obscured any trends resulting from rate of rainfall. It also appears that the effect of rate of rainfall is not linear, especially for chromium and copper. Increasing the rate of rainfall from 2,54 to $8,0 \mathrm{~mm} / \mathrm{h}$ tended to cause a greater reduction in leaching than did increasing the rainfall from 8,0 to $25 \mathrm{~mm} / \mathrm{h}$. Leaching of arsenic, chromium and copper was greatest from the $0,5 \%$ CCA-C solution concentrations, but the effect of rainfall rate was similar to that observed for the $1 \%$ and $2 \%$ solution concentrations. Although counterintuitive, greater leaching with lower CCA concentrations has been reported previously (Cooper 2003, Lee et al. 1993, Taylor and Cooper 2005). Solution concentration affects the $\mathrm{pH}$ of the treatment solution and the types of reaction products that form within the wood (Lebow 1996). A 0,5\% CCA-C solution is lower than typically used for commercial treatments, but was incorporated in this study to evaluate higher preservative release rates.

These findings corroborate previous field research suggesting that leaching from decking may be greatest in climates with extended periods of light, drizzly rainfall. Evans (1987) found that run-off from CCA treated Pinus sylvestris (Scots pine) roof boards contained higher concentrations of copper, chromium and arsenic when exposed to drizzling rain than to heavy showers. A similar effect was suggested by Cockroft and Laidlaw (1978). A previous study of sections of CCA treated decking exposed in this type of climate (western Oregon) did report slightly higher release rates than those detected in the slowest rainfall rates evaluated in this study (Lebow et al. 2000). In contrast, leaching would be minimized in climates where rainfall tends to occur in short, heavy showers. It is not surprising that, for a given amount of rainfall, more leaching would occur at slower rainfall rates. At faster rates of rainfall the water would have less contact time with the wood, and a higher proportion of water would run-off the specimens without causing leaching. The lack of effect of rainfall rate observed in an earlier laboratory study (Simonsen et al. 2008) may be a function of the type of preservative, wood species or study methodology. That study evaluated an oil-based preservative (pentachlorophenol) applied to Pseudotsuga menziesii (Douglas-fir), a wood species with limited permeability. The rainfall rates evaluated also differed, with the lowest rainfall rate evaluated in that study $(20 \mathrm{~mm} / \mathrm{h})$ approximately equivalent to the highest rainfall rate evaluated in the research reported in this paper. Specimens in the Simonsen, et al. 2008 study had also been pre-leached prior to rainwater exposure in an effort to simulate release from weathered wood. The role of rainfall rate in leaching from wood after extended exposure may warrant further evaluation. 


\section{Effect of Interval Between Rainfall Events}

Increasing the length of the time between rainfall events appeared to result in greater total leaching, especially at the slowest $(2,5 \mathrm{~mm} / \mathrm{h}$ ) rainfall rate (Table 2, Figure 1), although lack of replication prevented statistical analysis of this effect. Little resting period effect was evident at the highest $(25 \mathrm{~mm} / \mathrm{h})$ rainfall rate and it is possible that the short duration of the rainfall events at this rainfall rate did not provide sufficient moisture for subsequent diffusion of preservative elements within the wood. Specimen moisture content was not evaluated during the course of study. There was also little apparent difference in total leaching between specimens that had 2 versus 3 times the normal interval between rainfall events, regardless of rainfall rate. However, other differences in the effect of time between rainfall events are evident when compared as a function of rainfall volume (Figure 2). For specimens with 2 times the normal resting period the greatest increase in leaching occurred after $400 \mathrm{~mm}$ of rainfall, while for specimens with 3 times the normal resting period, increased leaching was primarily observed early in the test. This suggests that the longer resting periods allowed moisture to diffuse more deeply into the specimens after smaller amounts of rainfall. In the latter stages of the test specimens with 3 times the normal resting period had substantially less copper and chromium leaching than those without additional resting periods. The reason for this is unclear, but it may suggest that the greater moisture intrusion associated with the longer resting periods depleted the reservoir of poorly fixed copper and chromium in the specimens.
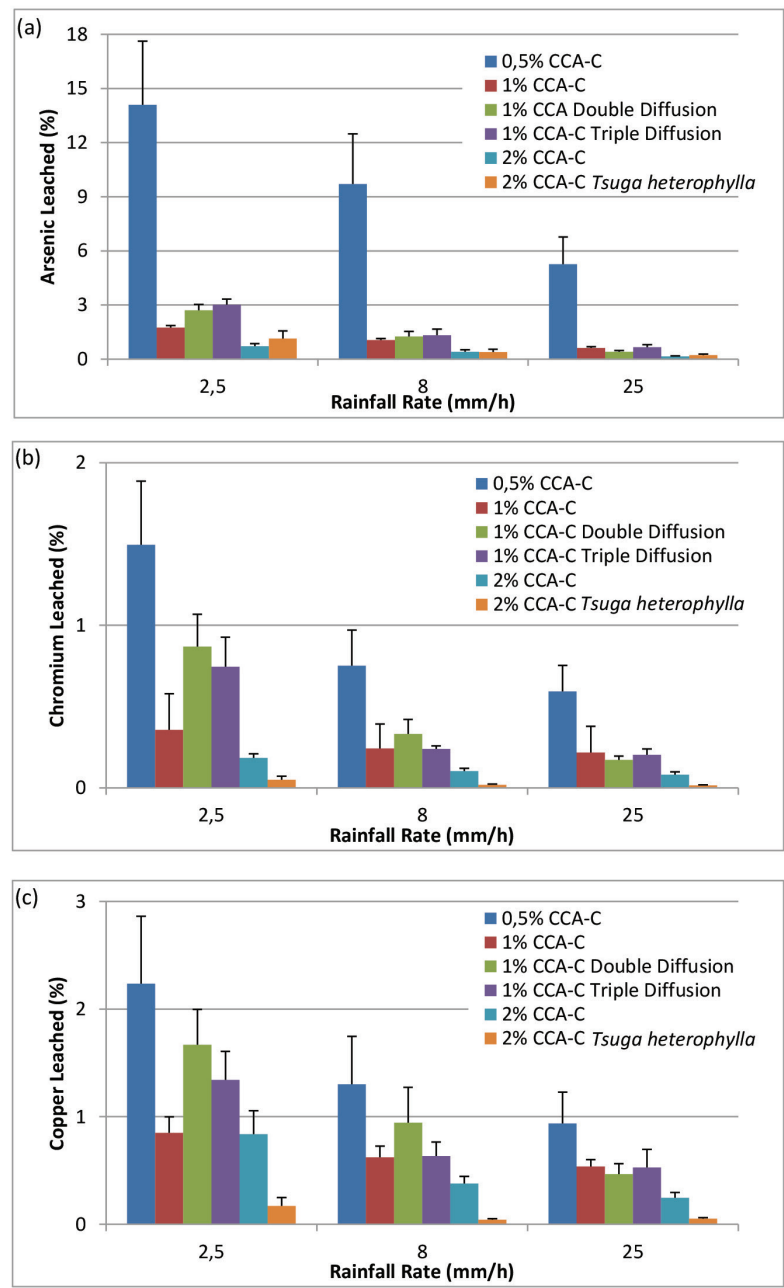

Figure 1. Percentage of arsenic (a), chromium (b) or copper (c) leached as a function of rainfall rate, solution concentration, resting period and wood species.

Error bars represent the standard error of the mean. 
Although doubling and tripling the time between rainfall events did extend the overall test time for those specimens to nearly 6 or 9 weeks, the duration of the exposures in these trials, and the time between rainfall events, was relatively short in comparison to natural exposures. Field leaching tests indicating that time between rainfall events influences leaching have been conducted over longer times periods, and included longer periods between rainfall events (Chung and Ruddick 2004, Hasan et al. 2010, Taylor and Cooper 2005). Time is required for mobilized preservative components to diffuse through the wood to the surface, and although the volume of rainfall was similar to a year of exposure, the length of time for diffusion of mobilized components through the wood was shorter than that of a specimen exposed for a year outdoors. It is also worth noting that the methods used in the study reported here minimized drying between rainfall events, at least in comparison to wood exposed outdoors. Morrell et al. (2010) generally did not observe an effect of interval between rainfall events on leaching from utility poles until the specimens were exposed to prolonged summer drought. Drying not only draws moisture to the wood surface, but also leads to the development of drying checks. No drying checks were observed in specimens in this study, regardless of the length of resting intervals. Checks may be an important factor in preservative leaching and redistribution because they increase surface area and allow precipitation ready access to the interior of treated products (Choi et al. 2004, Taylor and Cooper 2005).

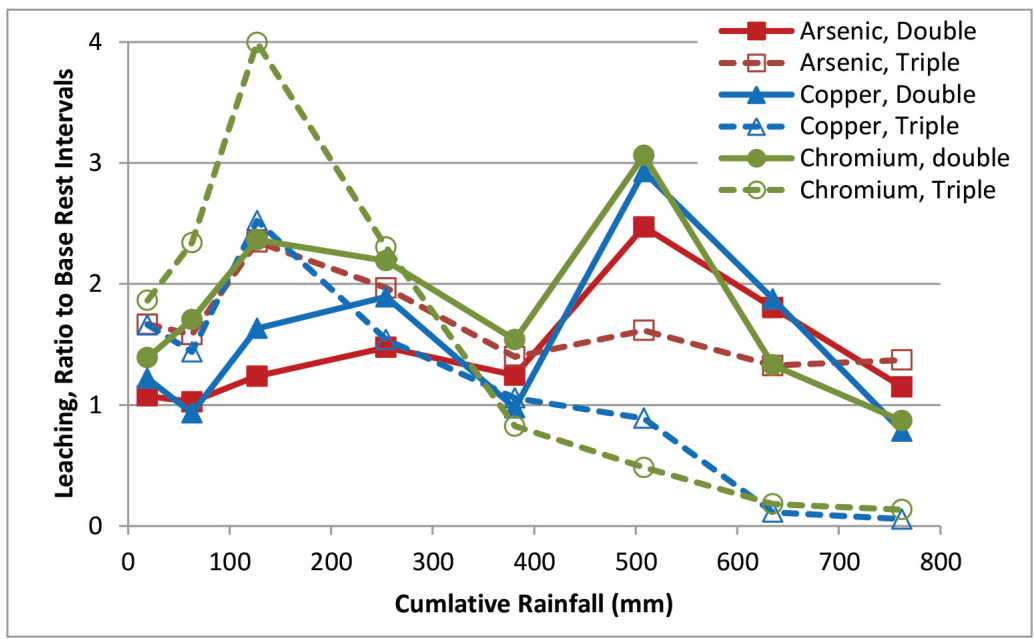

Figure 2. Ratio of arsenic, copper and chromium leaching from specimens with double and triple resting periods to that from base specimens without additional resting periods.

Data is for the lowest $(2,5 \mathrm{~mm} / \mathrm{h})$ rainfall rate.

It is important to note that this study utilized purified (deionized) water, which may not reflect some aspects of leaching in natural rainfall. The presence of inorganic ions in water has been reported to increase leaching from CCA-treated wood (Irvine et al. 1972, Plackett 1984) whereas they have been reported to decrease leaching with at least one type of preservative (Kartal et al. 2004, Kartal et al. 2007). The purified water used in this study also had nearly neutral $\mathrm{pH}(7,2)$ and little buffering capacity. Leaching of CCA is greatly increased when the $\mathrm{pH}$ of the leaching water is lowered to below 3 , and the wood itself also begins to degrade (Cooper 1991, Kim and Kim 1993). However, water $\mathrm{pH}$ ranges more typical of those found in rainfall are less likely to have a great effect on leaching (Murphy and Dickinson 1990). Cooper (1990) also noted that wood has some capability to buffer acid rain, and reported field observations in which water dripping from treated wood was consistently less acidic than the incoming rainfall. 


\section{CONCLUSIONS}

The findings of this study support field observations that, on a mass per unit rainfall basis, greater leaching occurs is with rainfalls of lower intensity. It is likely that the water has less contact time with the wood at faster rainfall rates, and that a higher proportion of water drains from the specimens without causing leaching. This finding suggests that leaching tests using simulated rainfall should be conducted using rainfall intensities at the lower end of those that are typical for the country or region. The findings also support the hypothesis that longer intervals between rainfall events can lead to increased leaching, although this effect was less evident with greater rainfall intensities. The results of this study did not define an optimum time between rainfall events, but do indicate that leaching does not increase proportionally with the length of the resting period. The role of time between rainfall events in leaching is likely to be a function of specimen dimensions as well as drying conditions. Incorporation of resting periods into simulated rainfall leaching methods presents a conflict between the objectives of accelerating the tests and obtaining representative leaching values. Because time is required for mobilized preservative components to diffuse through the wood to the surface, a compressed time frame could lessen leaching on a per unit rainfall basis. Further research may be warranted to assess the effect of drying periods between rainfall events, and to evaluate the role of precipitation patterns on leaching of other types of wood preservatives.

\section{ACKNOWLEDGEMENTS}

The author acknowledges the invaluable assistance of USDA, Forest Products Laboratory personnel Steven Halverson in preparing the test specimens and constructing the rainfall simulator, and Daniel Foster (retired) in conducting ICP analysis of CCA elements in the leachates.

\section{REFERENCES}

American Wood Protection Association. AWPA. 2013a. Standard Method for Accelerated Evaluation of Preservative Leaching. E11-12: Birmingham, AL. 658p.

American Wood Protection Association. AWPA. 2013b. Standard for Chromated Copper Arsenate Type C (CCA-D). P23-10: Birmingham, AL. 658p.

American Wood Protection Association. AWPA. 2013c. Standard Method for Analysis of Wood and Wood Treating Solutions by Inductively Coupled Plasma Emission Spectrometry. A21-08: Birmingham, AL. 658p.

Baines, E.F. 2005. A review of the current status of the estimation of emissions from preserved wood and their use in the environmental risk assessment of wood preservatives under the Biocidal Products Directive. IRG/WP 05-50224-7. International Research Group on Wood Preservation, Stockholm, Sweden.

Belford, D.S.; Nicholson, J. 1969. Emulsion additives for CCA preservatives to control weathering. Proc. Annual Meeting of the American Wood-Preservers' Association. Denver, Co. 65:38-46.

Brischke, C.; Rapp, A.O. 2008. Influence of wood moisture content and wood temperature on fungal decay in the field. Observations in different micro-climates. Wood Sci Technol 42(8):663-677.

Chinese National Standard. CNS. 2000. Qualitative Standards and Testing Methods of Wood Preservatives. CNS 6717. Bureau of Standards, Metrology and Inspection, Ministry of Economic Affairs (MOEA), Taipei, Taiwan.

Choi, S.; Ruddick, J.R.; Morris, P. 2004. Chemical redistribution in CCA treated decking. Forest Prod $J$ 54(3): 33-37. 
Chung, P.A.; Ruddick, J.N.R. 2004. Leaching of copper from ACQ treated wood exposed above ground. IRG/WP 04-50219. International Research Group on Wood Preservation, Stockholm, Sweden.

Cockroft, R.; Laidlaw, R.A. 1978. Factors affecting leaching of preservatives in practice. IRG/WP3113. Stockholm, Sweden: International Research Group.

Cooper, P.A. 1990. Leaching of CCA from treated wood. Proceedings, Annual Meeting of the Canadian Wood Preserver's Association. 11:144-169.

Cooper, P.A. 1991. Leaching of CCA from treated wood: pH effects. Forest Products Journal 41(1): 30-32.

Cooper, P.A. 2003. Leaching of CCA- facts and contradictions. Proceedings, Annual Meeting of the American Wood-Preservers Association. April 27-30, 2003. American Wood-Preservers' Association, Selma, AL. 99:73-99.

Cooper, P.A. 2011. Chapter 13. Review and comparison of test methodologies used to evaluate the leaching of wood preservatives. In: Managing Treated Wood in Aquatic Environments. Eds J. J. Morrell, K. M. Brooks and C.M. Davis. Forest Products Society, Madison, WI. pp.451- 472.

Cooper, P.A.; MacVicar, R. 1995. Effect of water repellents on leaching from CCA treated wood. Document No. IRG/WP 95-50044. International Research Group on Wood Preservation, Stockholm, Sweden.

Edlund, M.L.; Sundman, C.E. 1989. Moisture condition in treated wood exposed outdoors. A progress report. IRG/WP 3533. International Research Group on Wood Preservation: Stockholm, Sweden.

EN 84. 1997. Wood Preservatives - Accelerated ageing tests of treated wood prior to biological testingleaching procedure. CEN, Brussels, Belgium.

Evans, F.G. 1987. Leaching from CCA-impregnated wood to food, drinking water and silage. IRG/ WP/3433. International Research Group on Wood Preservation: Stockholm, Sweden.

Hasan, A.R.; Hu, L.; Solo-Gabriele, H.M.; Fieber, L.; Cai, Y.; Townsend, T.G. 2010. Field-scale leaching of arsenic, chromium and copper from weathered treated wood. Environmental Pollution 158(5):14791486.

Hedley, M.; Durbin, G.; Wichmann-Hansen, L.; Knowles, L. 2004. Comparative moisture uptake of Douglas fir and radiata pine structural lumber when exposed to rain wetting as an indicator of relative decay resistance. IRG/WP 04-20285. International Research Group on Wood Preservation: Stockholm, Sweden.

Hingston, J.A.; Collins, C.D.; J Murphy, R. J.; Lester, N. 2001. Leaching of chromated copper arsenate wood preservatives: a review. Environmental Pollution 111(1):53-66.

Irvine, J.; Eaton, R.A.; Jones, E.B.G. 1972. The effect of water of different composition on the leaching of a water-borne preservative from timber placed in cooling towers and in the sea. Material und Organismen 7: 45-71.

Japan Standards Association. JSA. 2004. Wood preservatives- Performance requirements and their test methods for determining effectiveness. JIS K 1571: Tokyo.

Kartal, S.N.; Dorau, B.F.; Lebow, S.T.; Green, F. III. 2004. The effects divalent cations on the leachability of wood preserving N, N-hydroxynaphthalamide (NHA). Forest Prod J 54(1): 80-84. 
Kartal, S.N.; Hwang, W.J.; Imamura, Y. 2007. Evaluation of effect of leaching medium on the release of copper, chromium, and arsenic from treated wood. Building and Environment 42(3):1188-1193.

Kim, J.J.; Kim, G.H. 1993. Leaching of CCA components from treated wood under acidic conditions. IRG/WP/93-50004. International Research Group on Wood Preservation: Stockholm, Sweden.

Lebow, S.T. 1996. Leaching of wood preservative components and their mobility in the environmentsummary of pertinent literature. Gen. Tech. Rep. FPL-GTR-93. Madison, WI: USDA, Forest Service, Forest Products Laboratory.

Lebow, S.T.; Foster, D.O.; Lebow, P.K. 2004. Rate of CCA leaching from commercially treated decking. Forest Prod J 54(2): 81-88.

Lebow, S.T.; Lebow, P.K.; Foster, D.O. 2000. Part I. Leaching and Environmental Accumulation of Preservative Elements. In: Forest Products Laboratory. Environmental Impact of Preservative Treated Wood in a Wetland Boardwalk. Res. Paper FPL-RP-582. Madison, WI: U.S. Department of Agriculture, Forest Service, Forest Products Laboratory. 126 p.

Lebow, S.T.; Lebow, P.K.; Foster, D.O. 2008. Estimating preservative release from treated wood exposed to precipitation. Wood and Fiber Science 40(4): 562-571.

Lebow, S.T.; Williams, R.S.; Lebow, P.K. 2003. Effect of simulated rainfall and weathering on release of preservative elements from CCA treated wood. Environ Sci Technol 37:4077-4082.

Lee, A.W.C.; Grafton, J.C.; Tainter, F.H. 1993. Effect of rapid redrying shortly after treatment on leachability of CCA treated Southern Pine. In: Winandy, J.; Barnes, M., Eds. Chromium-containing waterborne wood preservatives: Fixation and environmental issues. Madison, WI: Forest Products Society. pp.52-55.

Lindegaard, B.; Morsing, N. 2003. Natural durability of European wood species for exterior use above ground. IRG/WP 03-10499. International Research Group on Wood Preservation: Stockholm, Sweden.

Militz, H.M.; Broertjes, M.; Bloom, C.J. 1998. Moisture content development in lap-joints of different wood species in outside exposure trials. IRG/WP 98-20143. International Research Group on Wood Preservation: Stockholm, Sweden.

Mitsuhashi, J.; Love, C.S.; Freitag, C.; Morrell J.J. 2007. Migration of boron from Douglas-fir lumber subjected to simulated rainfall. Forest Prod J 57(12):52-57.

Morrell, J.J.; Chen, H.; Simonsen, J. 2004. Migration of metals from Douglas-fir lumber treated with ACZA using Best Management Practices: Preliminary tests. Proceedings, American Wood Preserver's Association. Annual Meeting, Vancouver, B.C. 100:158-161.

Morrell, J.J.; Love, C.S.; Freitag, C. 2010. Metal migration from Douglas-fir poles treated with ammoniacal copper zinc arsenate according to Best Management Practices. IRG/WP/10-50272. International Research Group on Wood Preservation: Stockholm, Sweden.

Morsing, N.; Lindegaard, B. 2004. Leaching of active components from preservative-treated timber: Stages $2 \&$ 3: Laboratory testing and comparison with semi-field testing. IRG/WP 04-20303. International Research Group on Wood Preservation: Stockholm, Sweden.

Murphy, R.J.; Dickinson, D.J. 1990. The effect of acid rain on CCA treated timber. IRG/WP/3579. International Research Group on Wood Preservation: Stockholm, Sweden. 
National Oceanic and Atmospheric Administration. NOAA. 2013. State of the Climate. National Overview- Annual 2012. National Climatic Data Center. [Accessed 08/22/13] [on line] <http://www.ncdc. noaa.gov/sotc/national/2012/13\#over>.

OECD. 2007. Estimation of Emissions from Preservative - Treated Wood to the Environment: Laboratory Method for Wooden Commodities that are not Covered and are in Contact with Fresh Water or Seawater. Test No. 313: Estimation of Emissions from Preservative - Treated Wood to the Environment. OECD Environment Directorate, Paris, France. 9p.

OECD. 2009. OECD Guidance on the Estimation of Emissions from Wood Preservative-Treated Wood to the Environment: for Wood held in Storage after Treatment and for Wooden Commodities that are not covered and are not in Contact with Ground. Series on Testing and Assessment No. 107. OECD Environment, Health and Safety Publications. OECD Environment Directorate, Paris, France.

Plackett, D.V. 1984. Leaching tests on CCA treated wood using inorganic salt solutions. IRG/WP/3310. International Research Group on Wood Preservation: Stockholm, Sweden.

Rapp, A.O.; Peek, R.D.; Sailer, M. 2000. Modeling of the moisture induced risk of decay for treated and untreated wood above ground. Holzforschung 54:111-118.

Ruddick, J.R. 2008. Chapter 17. Biocide depletion: chemical, physical and photodegradation. In: Development of Commercial Wood Preservatives: Efficacy, Environmental and Health Issues, Eds. T. P. Schultz, H. Miltz, M. H. Freeman, B. Goodell, and D.D. Nicholas. ACS Symposium Series 982. American Chemical Society, Washington, D.C. pp. 285-311.

Rydell, A.; Bergstrom, M.; Elowson, T. 2005. Mass loss and moisture dynamics of Scots pine (Pinus sylvestris L.) exposed outdoors above ground in Sweden. Holzforschung 59:183-189

Saladis, J.; Rapp, A. 2004. Moisture content and other tested values in Double layer tests of different size in Lithuania and Germany. IRG/WP 04-20299. International Research Group on Wood Preservation: Stockholm, Sweden.

Simonsen, J.; Chen, H.; Morrell, J.J.; Freitag, C.; Clauson, M. 2008. Pentachlorophenol migration from treated wood exposed to simulated rainfall. Holzforschung 62:608-612.

Schoknecht, U. 2005. Comparison of laboratory tests and field experiments for the estimation of emissions from treated wood. IRG/WP 05-50224:6. International Research Group on Wood Preservation: Stockholm, Sweden.

Schoknecht, U.; Wegner, R; Melcher, E. 2004. Experiences with the OECD guideline proposals for the estimation of emissions from preservative treated wood in the environment. IRG/WP 04-50209. International Research Group on Wood Preservation: Stockholm, Sweden.

Tao, W.; Shi, S.; Kroll, C.N. 2013. Influences of wood preservation, lumber size, and weather on field leaching of red pine lumber. Journal of Hazardous Materials 260 (15): 296-304.

Taylor, J.L; Cooper, P.A. 2005. Effect of climatic variables on chromated copper arsenate (CCA) leaching during above-ground exposure. Holzforschung 59: 467-472.

Temiz, A.; Yildiz, U.C.; Nilsson, T. 2006. Comparison of copper emission rates from wood treated with different preservatives to the environment. Building and Environment 41:910-914. 